\title{
Practice and Exploration of Global View of History in College History Teaching
}

\author{
Xianrong Yu \\ Ganzhou teachers college Ganzhou Jiangxi China.
}

\begin{abstract}
The concept of history refers to people's views on history, and the global view of history is one of the most important fields of research in the world. It not only requires us to study the trajectory of the world from a global perspective, but also emphasizes that it should not be limited to a narrow space to understand history. According to the concept of global history, every country is divided from split to whole and through global historical view to understand history. It not only helps students to set up a correct view of the situation, but also helps them to understand the history by means of dialectical means. This article briefly expounds the concept of global history, the feasibility of teaching the history of colleges and universities and the feasibility of the teaching of history in Colleges and universities. How to help students build a global historical view system.
\end{abstract}

Keywords: Global view of history; colleges and universities; history.

\section{全球史观在高校历史教学中的实践探索}

\section{余先荣 \\ 赣州师范高等专科学校 江西赣州 中国}

摘要: 所谓历史观, 是指人们对历史的看法, 而全球史观属于世界范围内的重要研究领域之 一, 它不仅要求我们从全局角度研究世界发展轨迹, 而且强调不应局限于某一狭小的空间内 去理解历史。根据全球史观的概念来看, 每个国家都是从分裂转为整体, 通过全球史观来了 解历史, 不仅有助于学生树立正确的大局观, 而且能帮助其利用辩证的手段了解历史, 本文 简要阐述了全球史观的概念、高校历史教学的可行性以及如何帮助学生构建全球史观体系等。

关键词：全球史观；高校；历史

\section{1. 引言}

全球史观不仅有助于学生了解历史, 同时帮助学生认识世界, 将各类因素联系起来。如今, 世界属于多元化的世界，信息技术已经充斥于各个领域，国家与国家之间的沟通更为频繁， 这便要求学生应当从全局的角度了解世界, 而不是片面的看待某个问题, 更便于学生深入甚 是历史。虽然当今世界并无过多的纷争, 国家间的关系较为和谐, 但是局部地区依然动荡, 大学生是世界末来发展的顶梁柱, 培养学生全球史观可以有助于其建立正确的三观, 因此, 全球史观在高校历史教学中占据重要地位。

\section{2. 全球史观}

\section{1 . 全球史观概述}

运用哲学的手段理解全球史观，抛弃传统、老旧的眼光去认识历史，应当拓宽视野，从全局 角度看清世界发展的历程。全球史观的概念是由英国某位历史学者提出, 他认为要想构建全 球史观应当超越种族以及地域的限制。美国的历史学者撰写出《全球通史》，其中采用全新 的视角以及手段来将世界看作一个整体, 从世界的角度而并非某个地区或者国家来认识人类 文明的变化, 他不仅将研究重点转向人类发展的历史节点, 同时阐述历史与运动的内在联系。 
《全球通史》的影响力巨大, 传播速度极快, 作者在大学里也曾开设全球史观课程。此外, 我国著名学者吴于虞先生也赞同这一举措。

2.2. 全球史观在高校历史教学中的可行性

如今, 世界是全球化的世界，人类的世界观早已不是当初那老旧的观念，国家内在联系更为 紧密, 因而地球村的概念被提出。构建出能反映世界历史变化的全球史观是当代给予历史学 科的重要目标。通过全球史观了解世界发展, 不仅是经济学领域以及历史学领域的研究方向, 同时也是我们应当具备的正确观念。

\section{3. 如何利用 “全球史观” 指导高校历史教学}

\section{1. 将 “全球史观” 渗透到历史教学活动中}

历史教学过程中, 教师理应发放部分全球史观的相关书籍, 促使学生从书本中获取有关信息, 例如: 美国著名历史学者阿诺思所撰写的《全球通史》, 这本教材属于极好的全球史观入门 学习书籍, 同时我国著名学者吴于虞先生所撰写的《世界史》也针对全球史观做出具体的讲 解, 学生会从中获取更加深层次的知识, 例如《世界观》中讲述到十五世纪的地理大发现是 人类历史上首次突破封闭状态的使其。高校历史教师可以用唯物主义史观来讲解历史问题并 培养学生的自主思考能力, 帮助其自行探索问题, 加强其辩证能力。

3. 2. 用全球史观帮助学生构建新的世界史体系

全球史观认为, 各个国家是从分离、封建逐渐演变成整体。根据上述观点, 我们能够将世界 史知识概括成两方面，第一方面是世界历史的纵向发展，它重点讲述人类的生产形势以及社 会形态意识的种种变化, 社会的发展是从原始社会转变为奴隶社会, 再从封建社会转化为资 本主义社会, 最终才到社会主义社会。第二方面是世界历史的横向发展, 主要是讲述不同地 区从封建转化为整体的过程。不论是纵向历史还是横向历史, 都属于世界历史的发展历程, 二者联系紧密又有区别。社会不断进步，科学技术的不断发展，西方国家的综合实力逐渐变 强, 版图逐渐扩张。西方资本趁势将科学技术、知识以及文明带给其他较为落后的国度, 进 而实现全球一体化。由此带来的好处数不胜数, 不仅推动了资本、人力资源、物资的发展, 同时帮助资本主义国家发展壮大，进而继续拓展版图，促使世界变化为有机的整体。因此， 历史教师在授课阶段应当将历史纵线以及历史横线讲述清楚, 帮助学生构建出完整的世界历 史体系。

3. 3. 用全球史观解读历史事件和历史现象

高校历史教师应当在课堂上引导学生运用全球史观学习历史知识。全球史观要求以是否促进 社会生产力的发展和交往为标准来评价历史事件和现象。例如: 全球史观认为第一次工业革 命有效加快西方资本主义国家的发展，同时提升资本主义国家的生产力。英国属于工业革命 的受益者, 其综合国力不仅大幅加强, 而且版图在不断扩张。十八世纪至十九世纪, 英国被 称为日不落帝国。此外，第二次工业革命依然以西方资本主义国家为首，帮其进一步提升国 力, 而且这次他们的版图扩张速度更快, 依然掀起瓜分世界的热潮, 资本主义市场以及体系 由此诞生, 世界也彻底变为一个整体。我们在评判某些历史事件时应当利用全球史观来深入 理解, 例如郑和下西洋以及哥伦布发现新大陆的历史事件, 它们均发生于同一时期, 但是哥 伦布的发现却远比郑和更具影响力呢? 郑和的发现也属于世界历史的壮举, 不仅覆盖规模巨 大, 而且地域广泛, 但是他只是明朝统治者为彰显自身强大以及搜集财产的附属品, 并未真 正对世界做出贡献。然而, 哥伦布发现的美洲大陆不仅帮助西欧国家不断扩张, 同时帮助资 本主义创建新的场地, 进而推动西方资本主义的发展。因此, 哥伦布的发现比郑和更具意义。

3. 4. 用全球史观去认识和评价历史人物

世界历史都是由人民所创造的, 各类英雄人物都在历史事件中展现出自身的价值, 推动历史 发展, 但是, 我们应当用辩证的视角来评价这些人物, 公平公正地看待他们所做出的历史贡 献。全球史观以是否能够促进生产力的发展和社会交往作为评价历史人物的标准。例如: 清 朝著名官僚李鸿章被大部分人当成卖国贼, 认为其签署大量的不平等条件以伤害国家利益。 
然而, 我们更应当认清他的所作所为促进中国的发展。李鸿章与外国使臣交谈过程中, 他发 现中国与其他国家存在巨大的差距, 因此联合张之洞等人发起洋务运动, 大量购买西方科学 技术以及先进设备, 帮助中国构建第一代工业体系, 有效推动民族资本主义的诞生以及发展, 因此，我们不应只看到李鸿章的过失，更应了解到他所做出的各种贡献。又例如：现代人在 评价毛主席时会有不同的意见, 部分人认为毛主席阻碍国家发展, 部分人认为毛主席构建新 中国，举世无双。我们也应当辩证地看待这个问题，首先，毛主席发起新民主主义革命并构 建新中国, 绝对是伟大的革命家，但是他所倡导的文化大革命等活动也造成中国经济发展较 慢, 甚至下滑。著名学者郁达夫先生曾讲述到: 如果一个民族缺少英雄是悲哀的, 但是一个 民族拥有英雄却不知道尊重英雄, 那么这个民族只能沦为奴隶之邦。综上所述, 我们在评判 英雄人物时应当从好坏两方面去分析，不能单纯地从某一角度去看待。

\section{4. 结语}

综上所述, 全球史观在高校历史教学中占据重要地位。教师应当培养学生用全球史观学习历 史知识, 构建出完善的历史知识体系, 深入学习世界历史不同时期、不同国家的发展历程, 产生思维的碰撞, 进而增强自主思考以及辩证思维的能力。同时应该运用辩证的角度去评价 历史人物, 不能片面地认识英雄人物, 进而更好地学习历史知识, 增强学生的全球意识, 便 于他们毕业以后更好地融入社会。

\section{References}

[1]. Chen Paying Marx's view of world history and the construction of the community of human destiny [J]. Yunmeng journal, 2018 (1).

[2]. Zhao Liang. On teaching methods of global history in high school [J]. Youth age, 2018 (1).

[3]. Qin Don fang. Inspired by the concept of civilization history, contemporary young college students continuously build their own world view. [J]. literature education (II), 2018 (1): 72-73.

[4]. Xu Guoyu, Zhang Qian Ming. The significance of Marx's view of history in the new era from the perspective of practice -- Based on the "German Ideology" as an example of the Journal of the Party School in Yanbian, 2018 (1).

[5]. Yu Land. Analysis of contemporary college students' Outlook on history education [J]. theory, 2018 (1). 